\title{
Changes in population characteristics and structure of the signal crayfish at the edge of its invasive range in a European river
}

\author{
Sandra Hudina ${ }^{1 *}$, Karlo Hock ${ }^{2}$, Krešimir $\breve{Z g a n e c}^{1}$ and Andreja Lucić ${ }^{1}$ \\ ${ }^{1}$ Faculty of Science, University of Zagreb, Rooseveltov trg 6, 10000 Zagreb, Croatia \\ 2 Department of Ecology, Evolution and Natural Resources, Rutgers The State University of New Jersey, New Brunswick, \\ NJ 08901, USA
}

Received 18 June 2011; Accepted 6 September 2011

\begin{abstract}
The ability of rapid range expansion is one of the key determinants of invasive species success. In order to investigate potential drivers behind the rapid spread of invasive species, we explored changes in population characteristics and structure along the invasion pathway of a successful invader in European freshwaters, the signal crayfish (Pacifastacus leniusculus). Diverse population parameters such as relative population abundance, size and sex structure, differences in morphometry and frequency of injuries were compared between signal crayfish population samples at three uniformly distributed segments (approximately $40 \mathrm{~km}$ apart) in the lower section of the Mura River, which differed in time since invasion. Examined signal crayfish populations exhibited notable differences, with more recently established populations toward invasion front characterized by lower abundance and male-biased sex ratios, which highlighted males as initial dispersers. We also recorded significant increase in the relative claw size, a competitively advantageous and allometric trait for males, in more recently established populations away from source population. The recorded differences in population structure and male morphometry along the invasion pathway could lead to important clues about dynamics of range expansion and population establishment, highlighting the traits that promote dispersal and better response to local conditions in new habitats. Established differences can also provide insights into the development of targeted management responses aimed at invasive species control.
\end{abstract}

Key words: Invasive species / range expansion / time since establishment / population characteristics / crayfish

\section{Introduction}

Invasive alien species are affecting ecosystems globally and are considered a major component of human-induced environmental change (Sala et al., 2000), contributing to the biodiversity loss, ecosystem degradation and impairment of ecosystem services worldwide (Pyšek and Richardson, 2010). Their invasion success depends on a suite of key attributes, which include the ability of rapid range expansion along with other life history traits that facilitate population establishment and growth (Kolar and Loge, 2002; Marchetti et al., 2004; Rehage and Sih, 2004; Lockwood et al., 2007). Identification of traits promoting invasion success and determinants of dispersal dynamics are essential in attempts to understand the exceptional speed at which invasive species are able to expand their range. Such studies have recently become increasingly present in the field of aquatic invasions (cf. Gutowsky and Fox, 2011), partly due to high susceptibility of freshwater

\footnotetext{
*Corresponding author: shudina@zg.biol.pmf.hr
}

ecosystems to invading species (Strayer, 2010) and the extensive and continually increasing rate of unintentional and intentional non-indigenous species introductions (Ricciardi, 2001).

Crayfish are among the most widely translocated aquatic invertebrates, and the signal crayfish (Pacifastacus leniusculus, Dana) currently present in 27 European countries, is the most widespread non-indigenous crayfish in Europe (Holdich et al., 2009). Along with habitat loss, signal crayfish represents the main threats to native European crayfish species (Weinländer and Füreder, 2009). Its ability to successfully outcompete native crayfish species due to its aggressiveness (e.g., Söderbäck, 1991; Usio et al., 2001; Pintor et al., 2008), advantageous life history traits such as fast growth rate, high fecundity and early maturation (Souty-Grosset et al., 2006), and transmission of diseases such as crayfish plague (e.g., DiéguezUribeondo, 2006), can enhance its potential to drastically affect native crayfish populations. In addition, it exhibits adverse impacts on other biota (e.g., macroinvertebrates and fish: Griffiths et al., 2004; Crawford et al., 2006) and 
ecosystem functioning through combined effects of consumption, bioturbation and burrowing activity (StancliffeVaughan, 2009). Introductions followed by high dispersal rates are considered to be one of the major causes of its widespread distribution in many parts of the world (e.g., Pintor et al., 2009). In some European river systems, the range expansion of signal crayfish has been very fast, especially in downstream direction, reaching up to 18-24.4 km.year ${ }^{-1}$ in the lower reaches of the large European river, the Mura River (Hudina et al., 2009).

Despite such high recorded rates of range expansion, relatively little information are available on the changes in signal crayfish population characteristics and structure along its invasion pathway. The process of invasive species range expansion is expected to result in dynamic shifts in individual traits and population characteristics. Such shifts arise in response to both selection of specific dispersal phenotypes from a source population (Rehage and Sih, 2004; Clobert et al., 2009; Pintor et al., 2009; Cote et al., 2010a, 2010b) and novel local conditions and tradeoffs individuals encounter during population establishment and growth, as the species spreads into new habitats (e.g., Bøhn et al., 2004; Burton et al., 2010; Phillips et al., 2010). Moreover, population characteristics will vary over time as a species becomes established, in response to changes in population size and, consequently, resource availability (e.g., Bøhn et al., 2004). For instance, as crayfish growth rate is density dependent (Guan and Wiles, 1999; Westman and Savolainen, 2002), it is expected to be higher in newly established populations of lower density. This could result in the higher frequency of larger individuals in such populations in comparison with high-density populations established for longer periods (cf. Gutowsky and Fox, 2011). Therefore, the potential differences in population characteristics in spatially distant invasive crayfish populations along invasion pathway will reflect the spatial component of invasion dynamics (dispersal process) as well as temporal component (time since invasion and population establishment), provided that such distances are higher than estimated yearly dispersal rates and that species is spreading naturally without subsequent introductions.

Identification of population variability along invasive range is crucial for understanding the underlying drivers of invasive species dispersal, for designing targeted management approaches aimed at their control and for predicting their future distributions. Only a few available studies assess such shifts in population characteristics along an invasion pathway (e.g., Phillips, 2009; Gutowsky and Fox, 2011); however, no such data are available for invasive crayfish. To fill this gap, we investigated differences in population characteristics of invasive signal crayfish between three different segments at the edge of its invasive range in the Mura River, which differed in time since its establishment. At examined segments, we recorded diverse population parameters, such as relative population abundance, sex and size structure, as well as morphometric characteristics and frequency of injuries. We expected that (i) traits promoting invasion success will be more pronounced toward the invasion front, making such recently established populations significantly different from populations established for a longer period and that (ii) dynamics of range expansion and population establishment will be reflected in population structure along different segments of invasive range which contain populations of different age. We discuss inter-population differences in light of the trade-offs individuals face at different segments of invasive range and in populations at different stages of establishment, selection of specific dispersal phenotypes and also the potential management implications. This study sheds new light on the potential mechanisms behind the observed rapid range expansion of invasive species such as signal crayfish.

\section{Methods}

\section{Study system and sampled population}

The Mura River is the largest tributary to the Drava River, with a length of $444 \mathrm{~km}$ and a catchment area of $14304 \mathrm{~km}^{2}$. A proportion of $70 \%$ of its catchment belongs to Austria $\left(10013 \mathrm{~km}^{2}\right)$, while the lower part of Mura is situated in Slovenia $\left(1393 \mathrm{~km}^{2}\right)$, Croatia $\left(987 \mathrm{~km}^{2}\right)$ and Hungary $\left(1911 \mathrm{~km}^{2}\right)$. The hydrological regime depends on the snow-melting season in Austria, with usual higher discharge during spring months (March-May) and lower discharge in the winter period (Globevnik and Kaligarič, 2005). The climate ranges from alpine to continental (spring at $1898 \mathrm{~m}$ a.s.l. in the eastern edge of the Lower Tauren Alps in Austria/mouth Legrad, Croatia $132 \mathrm{~m}$ a.s.1.), with the dominating mild-continental and partly humid climate (average annual temperature $10.9^{\circ} \mathrm{C}$ and an average rainfall of $600-750 \mathrm{~mm}$.year $\left.{ }^{-1}\right)$, as in the entire Drava River basin (Sommerwerk et al., 2009).

Signal crayfish has been present for several decades in the upper section of the Mura River (Austria) as a consequence of its illegal introductions in the 1970s (Pöck1, 1999; Holdich et al., 2009). Its dispersal to lower sections of the Mura River (Slovenia and Croatia) is considered to represent a continuous range expansion (cf. Hudina et al., 2009). In this study, we examined signal crayfish populations in the lower section of the Mura River (last $80 \mathrm{~km}$, Fig. 1), where the highest dispersal rates of signal crayfish in Europe have been recorded by previous studies (Hudina et al., 2009). Signal crayfish populations at the most upstream sites of this section have been established for over 5 years and have reached relatively high population densities and balanced sex structure (Hudina et al., 2011). Therefore, the most upstream examined site is considered to represent a source population in the examined river section.

\section{Inter-population comparisons}

In order to analyze potential inter-population variability in parameters such as relative population 


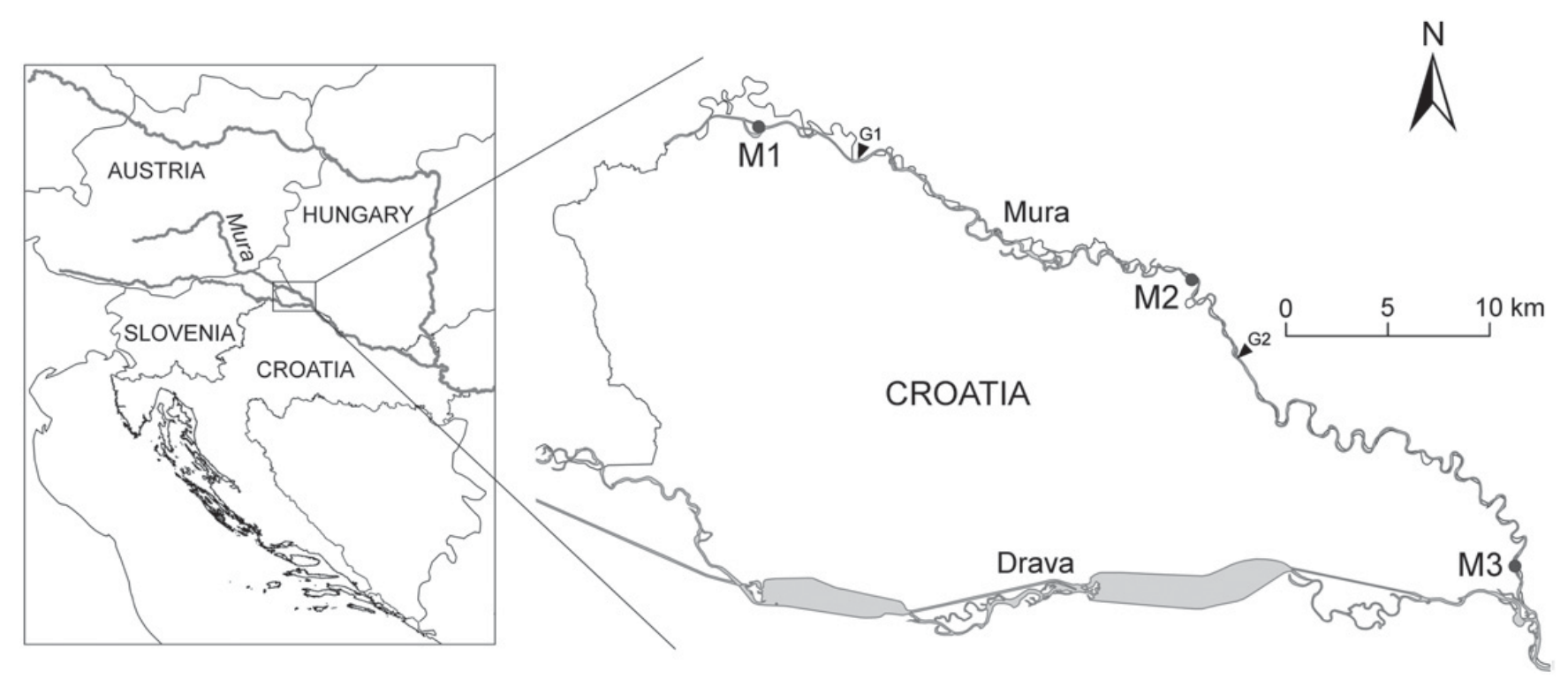

Fig. 1. The position of examined sites in the lower section of the Mura River, Croatia. M1 represents the most upstream examined site (source population), M3 invasion front, while M2 represents the intermediate point between these two sites. G1 and G2 represent the two gauging stations from which continuous measurements of water temperature and discharge were obtained.

Table 1. Water temperature and discharge measured continuously on a daily basis at the two gauging stations in the analyzed section of the Mura River. Station G1 is located at $6 \mathrm{~km}$ downstream from M1 and G2 at $7 \mathrm{~km}$ downstream from M2.

\begin{tabular}{lcc}
\hline & G1 & G2 \\
\hline Mean annual discharge (2000-2009), $\mathrm{m}^{3} \cdot \mathrm{s}^{-1}$ & 154.5 & 160.8 \\
Min-max mean annual discharge, $\mathrm{m}^{3} \cdot \mathrm{s}^{-1}$ & $95-228$ & $100-235$ \\
Min-max discharge (2000-2009), $\mathrm{m}^{3} \cdot \mathrm{s}^{-1}$ & $38-1196$ & $42-1225$ \\
Mean monthly discharge in the research period (May-Nov 2009), $\mathrm{m}^{3} \cdot \mathrm{s}^{-1}$ & 264.3 & 270.7 \\
Min-max mean discharge in the research period (May-Nov 2009), $\mathrm{m}^{3} \cdot \mathrm{s}^{-1}$ & $134-207$ & $135-230$ \\
Mean annual water temperature $(2005),{ }^{\circ} \mathrm{C}$ & 10.2 & 10.1 \\
Min-max water temperature (2005), ${ }^{\circ} \mathrm{C}$ & $0.6-18.6$ & $0.2-22.2$ \\
\hline
\end{tabular}

abundance, size and sex structure, morphometry and frequency of injuries along signal crayfish invasion pathway, we identified three points of its range (Fig. 1): the source population at the most upstream site of the examined section at 80 river kilometers (rkm) from the confluence with the Drava River (Mura 1 or M1), invasion front (Mura 3 or M3; rkm 3) and the intermediate point between these two extremes (Mura 2 or M2; rkm 44). These sites were chosen on the basis of previous research on signal crayfish distribution in the Mura River (Hudina et al., 2009), which identified invasion front (M3) at $3 \mathrm{~km}$ upstream from the mouth of the Mura River. Sites were located approximately $40 \mathrm{~km}$ apart, which is around double the value of estimated dispersal rate in this section of the Mura River (18-24.4 km.year ${ }^{-1}$ ). Therefore, examined crayfish populations varied in time since population establishment, with population at M1 established for the longest period ( > 5 years; Hudina et al., 2009), and the population at M3 founded most recently.

Water temperature and discharge measured continuously on a daily basis at the two gauging stations (G1 and G2 in Fig. 1) were very similar (Table 1). Station G1 is located $6 \mathrm{~km}$ downstream from M1 and G2 $7 \mathrm{~km}$ downstream from M2. Tributaries between these two gauging stations are rare and bring only a small amount of water to the Mura River, which can be inferred from slight increase of discharge at G2 (Table 1). River segment between gauging station G2 and site M3 has even less small tributaries. Hence, it can be assumed that all three examined river segments are very similar in terms of temperature and flow conditions. Furthermore, examined sites were of the same length $(100 \mathrm{~m})$ with the similar river width (average river width $75 \mathrm{~m}$ at M1, 73 at M2 and 64 at M3) and were all characterized by sparsely developed riparian vegetation, with dominating willows (Salix sp.) and steep banks with revetments. Stone blocks up to $40 \mathrm{~cm}$ along with gravel and sand dominated in the substrate composition of all examined sites. Also, the presence and abundance of potential crayfish predators such as European otter (Jelić, 2009) and fish (Sallai, 2002; Mrakovčić et al., 2008) is similar in the lower section of the Mura River. Based on former literature data and the overall similarity of studied sites, there was no reason to assume the existence of greater differences in predatory pressure between our sites. 
Assuming such similar characteristics, we expected that observed population size and structure patterns at examined sites did not reflect differences other than invasion dynamics.

Sites were examined monthly for 6 months in a period of increased crayfish activity (May-November 2009) with LiNi traps (Westman et al., 1978) baited with meat. During each trapping session, LiNi traps were set at the same position and in similar microhabitats within all examined sites (close to the banks and large stone blocks in low velocity areas), for at least two trapping nights. Altogether six traps were set at M1 and M2 during each trapping occasion (approximately $15 \mathrm{~m}$ apart), while at M3 catch effort was slightly increased (eight traps; approximately $12 \mathrm{~m}$ apart) due to expected low crayfish density at this site. While trapping was performed for longer periods, only months for which all crayfish population parameters could be measured at all three examined sites were analyzed further (August, October and November), except for analysis of relative population abundance where all six examined months were taken into account.

For every trapping session, we recorded the catch per unit effort (CPUE; equal to the number of caught crayfish per trap per number of trapping nights) for each site. CPUE is a frequently used measure of relative crayfish abundance (Dana et al., 2010), and was found positively correlated with other measures of population density (Dorn et al., 2005). Therefore, obtained CPUE was used to compare relative abundance of catchable population samples between the sites. All caught crayfish were sexed, weighted (W) and eight morphometric parameters were measured to the nearest $1 \mathrm{~mm}$ : total length (TL), carapace length (CL) carapace width, abdomen length, abdomen width, claw length (CLL), claw width (CLW), claw thickness (CLT; equal to claw height in Sint et al., 2007). Claw parameters (length, width and thickness) were used to calculate claw volume $(\mathrm{CLVol})$. As allometric growth of certain body parameters (claws in males, abdomen in females) is a determinant of sexual dimorphism and reflects the onset of sexual maturity (Harioglu and Holdich, 2001; Streissl and Hödl, 2002), both sexes were divided into two size classes: size class 1 , animals $<9$ cm TL (potentially immature individuals); and size class 2 , animals $>9 \mathrm{~cm}$ TL (mature individuals). Such classification was based upon the large size of the smallest caught mature female recorded during year cycle research at M1 $(85 \mathrm{~mm}$ TL; Hudina et al., 2011) which was close to the upper range of signal crayfish size at maturity recorded in the literature (6-9 cm TL; Westman et al., 1999; SoutyGrosset et al., 2006). Finally, in order to take into account the potential allometric growth in adult (i.e., mature) males and females, measured claw and abdomen parameters were compared between the sites as relative proportion of each respective parameter to TL.

Lastly, all animals were inspected for the presence of injuries. Injuries are often the consequence of aggressive interactions between crayfish which usually increase with population density (Skurdal et al., 1988). Since claws represent a valuable and frequently damaged tool in aggressive interactions between crayfish (Schroeder and Huber, 2001), the proportion of all injuries and claw injuries in a population was used as an indirect measure of the intensity of resource competition (Söderbäck, 1995; Hudina et al., 2011), and was compared between examined population samples. Once caught, all measured animals were removed from the population to prevent recaptures.

\section{Statistical analyses}

Inter-population comparisons were performed using parametric tests (Student's $t$-test) when the assumptions of normality of data and homogeneity of variance were met on either raw or log-transformed data. Where transformed data did not meet the assumptions necessary to use parametric analyses, their non-parametric analogs (Mann-Whitney U-test for comparisons between two samples, Kruskal-Wallis ANOVA for comparisons between multiple samples with post-hoc multiple comparisons of the mean ranks; Zar, 1996) were used instead. Comparisons of sex and size structure and injury frequencies between examined sites were performed using Yates' chi-square test (Zar, 1996). In inter-population comparisons, parameters measured at each site during three (August, October and November) or six (May-November 2009) trapping occasions were pooled together. The level of significance for all performed statistical tests was set at $P<0.05$.

\section{Results}

During the 6-month trapping period (May-November 2009), 355 animals in total were caught at all examined sites, $84 \%$ of which were trapped during three trapping occasions (August, October and November 2009) when crayfish were caught at all three examined sites. Out of the total of 299 individuals caught in these three trapping periods and used in inter-population comparisons between all examined sites, 211 individuals $(70.6 \%)$ were captured from the source population at M1 (Table 2). Only 3.3\% of all caught animals were captured at the invasion front at M3 (Table 2).

Comparisons between population samples at three different segments of the invasive range showed a statistically significant difference in CPUE between examined sites during the trapping period of 6 months (May-November 2009; Kruskal-Wallis $\left.H_{(2,18)}=7.72, P=0.021\right)$, with the decrease in the CPUE from the source population sample at M1 toward the invasion front at M3 (Fig. 2). Post-hoc multiple comparisons of mean ranks revealed that these differences stemmed from differences between populations samples at M1 and M3 (multiple comparisons of mean ranks; $P=0.017$ ). Such significantly lower CPUE at M3 coupled with the reported history of signal crayfish dispersal in the lower section of the Mura River and no signal crayfish captures downstream from this area confirms that 
Table 2. Average total length (TL), with TL range given in parentheses, of both sexes and average egg number and diameter for berried females caught at each examined site within three trapping occasions (August, October and November 2009). $N$ represents the number of caught individuals of each group. $\mathrm{N} / \mathrm{A}=$ data not available.

\begin{tabular}{|c|c|c|c|c|c|c|}
\hline Site & $N$ & M1 & $N$ & M2 & $N$ & M3 \\
\hline Average TL males per $\mathrm{mm}$ & 103 & $110.9(73.5-144.8)$ & 52 & $111.6(84.5-131.9)$ & 8 & $101.8(86.8-118.1)$ \\
\hline Average TL females per $\mathrm{mm}$ & 110 & $109.3(76.4-131.9)$ & 24 & $105.3(77.7-129.6)$ & 2 & $98.9(95.5-102.3)$ \\
\hline Average egg number & & $345(214-400)$ & & $216(83-348)$ & & $\mathrm{N} / \mathrm{A}$ \\
\hline Average egg diameter per $\mathrm{mm}$ & & $2.37(2.13-2.52)$ & & $2.33(2.27-2.40)$ & & $\mathrm{N} / \mathrm{A}$ \\
\hline
\end{tabular}

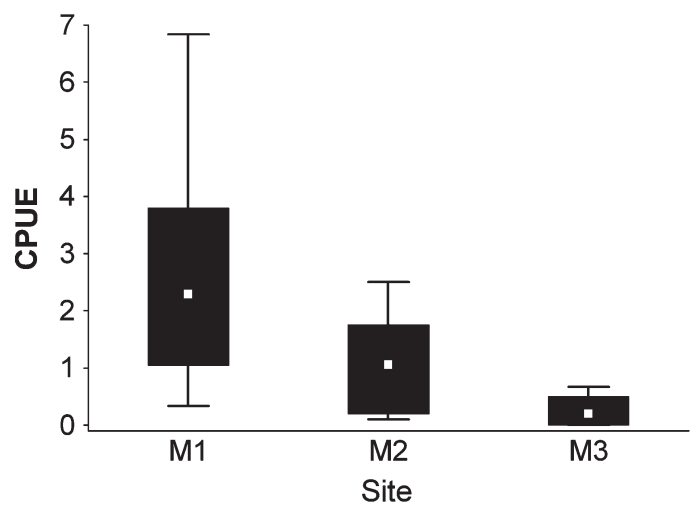

Fig. 2. Differences in catch per unit effort (CPUE; equal to the number of caught crayfish per trap per number of trapping nights) between examined sites during same trapping periods (August, October and November 2009). The boxes show medians and quartiles, whiskers show minimum and maximum.

the selected site indeed represents the edge of its invasive range, i.e., invasion front.

Statistically significant difference in sex structure was recorded between examined sites for the three examined months $\left(\chi^{2}=11.31, P=0.003\right)$ with the number of caught males in the catch increasing toward the invasion front (Fig. 3). Similarly, when 6 months of trapping (May-November 2009) were compared between M1 and M2 sites, sex ratio differed significantly $\left(\chi^{2}=5.76\right.$, $P=0.016)$ as well and followed the same pattern, with more males featured in the catch at the site M2 (1.01:1 $\mathrm{M}: \mathrm{F}$ at M1 and 1.89:1 at M2). Population size structure, examined through frequencies of caught animals in two identified size classes at each site, did not differ significantly between the sites for the composite sample of 3 months $\left(\chi^{2}=5.13, P=0.077\right)$. However, the proportion of size class 1 animals in the catch increased toward the invasion front $(5.2 \%$ of all caught animals at M1, 10.5\% at M2 and $20 \%$ at M3).

When comparing measured parameters of animal size and weight, males and females of both size classes were treated separately due to statistically significant differences in some (CL and TL for size class 1 animals; Mann-Whitney $U$-test: $P<0.05)$ or all measured parameters (size class 2 animals; $t$-test: $P<0.05$ ) between sexes. Morphometric characteristics and weight of animals of both size classes were compared only between the sites M1 and M2 due to the small number of individuals of both sexes captured at invasion front (six males and two females

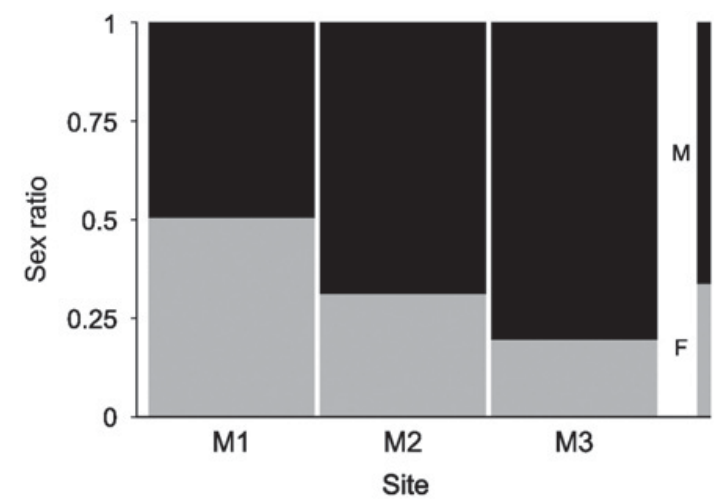

Fig. 3. Sex ratio $(M=$ males; $F=$ females $)$ at three examined sites during the same trapping periods (August, October and November 2009). The bar on the right shows the sex ratio for a composite sample of all three sites.

in total). Out of all measured parameters, size class 1 males at M1 and M2 differed significantly only in the relative CLL $(U=53.00, P=0.009)$, it being higher at M2 (Fig. 4(a)). The similar pattern of increase in the relative CLL was also observed at the invasion front (M3). When compared with other groups, M3 data (relative CLL 0.441 and 0.460$)$ were above the upper quartile of the M1 (M1 median of 0.42 ; interquartile range of $0.390-0.434$ ) and around median or above the upper quartile of M2 (M2 median of 0.44 ; interquartile range of $0.434-0.457$ ), suggesting a tendency toward above-average relative CLL for M3 males in comparison with M1 (Fig. 4(a)). No statistically significant differences between M1 and M2 sites in any of the measured parameters of animal size and weight were observed in size class 1 females.

In size class 2 males, statistically significant difference between the M1 and M2 sites was recorded for all measured parameters of claw size (relative CLL: $U=2463$; $P=0.006$; relative CLW: $U=2571, P=0.017$; relative CLT: $U=1665, P=0.003$; relative CLVol: $U=1686$, $P=0.004$ ), which were all higher at M2 (Fig. 4(b)). Due to a similar pattern of observed differences between two sites for each measured claw parameter, only relative CLL is presented in Figure 4(b). When compared with other groups, all M3 data showed a similar distribution pattern as that demonstrated in Figure 4(b) for relative CLL. Relative CLL data at M3 (range 0.41-0.51) were distributed both above and below the median of M1 (M1 median of 0.48 ; interquartile range of $0.455-0.514$; Fig. 4(b)). Therefore, no clear trend of relative claw size 
(a)

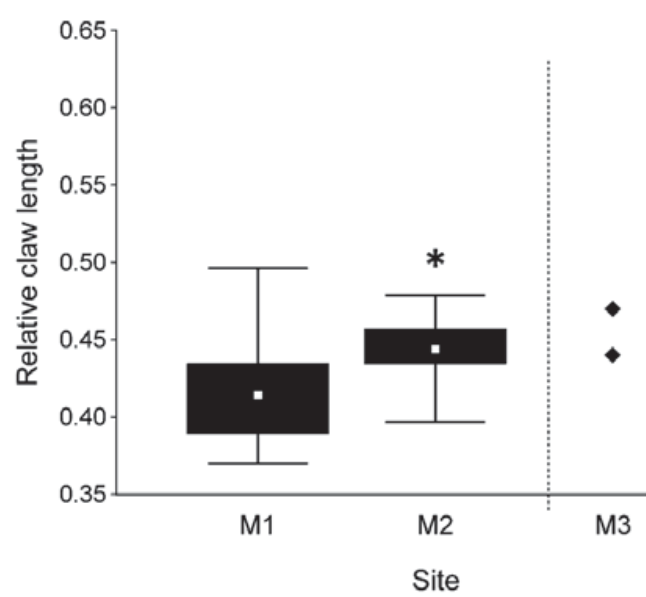

(b)

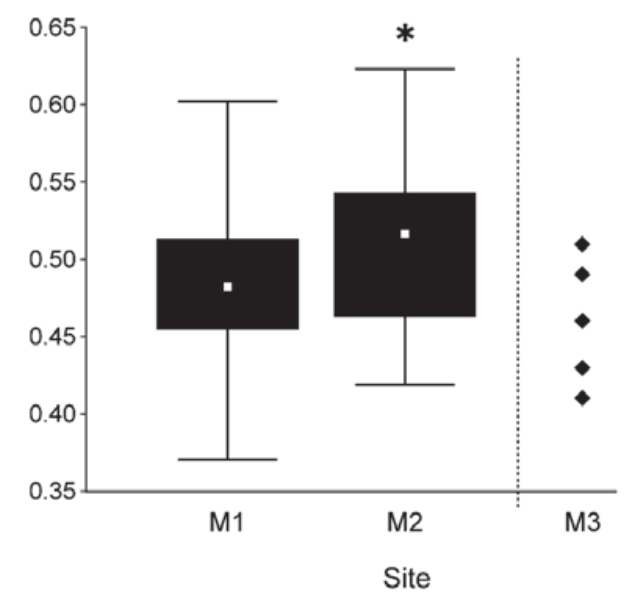

Fig. 4. Relative claw length (CLL) at two segments of signal crayfish invasive range for size class 1 (a) and size class 2 (b) males. Data for the third site (M3) were added for reference only and were not included in the quantitative analyses. The boxes show medians and quartiles, whiskers show minimum and maximum. *Indicates significantly higher relative CLL.

was detected at the M3 in comparison with other two sites. No statistically significant differences between M1 and M2 sites in any of the measured parameters of animal size and weight were observed in size class 2 females.

Analyses of injuries in both size classes revealed no significant differences between males and females in the number of injured animals, injury numbers, number of animals with claw injuries and claw injury numbers $(P>0.05$ for all $\chi^{2}$ tests). Also, no statistically significant differences in examined parameters (number of injured animals, injury number, number of animals with claw injuries, claw injury number) were recorded between the sites both for size class 2 male and female crayfish ( $P>0.05$ for all $\chi^{2}$ tests). Injury parameters for size class 1 animals were not analyzed statistically due to extremely small number of both sexes at the invasion front. Proportions of injured size class 1 males and females were equal (18.2\% of all size class 1 animals), while proportions of injured size class 1 animals showed a tendency of increase toward the invasion front $(18.2 \%$ at $\mathrm{M} 1,25 \%$ at M2 and $50 \%$ at M3).

\section{Discussion}

Our study detected several differences among signal crayfish population samples caught from different locations along the edge of its invasive range in a European river, and thus from populations at different stages of establishment. Examined population samples exhibited a decrease in the relative population abundance toward the invasion front and changes in sex structure and male morphometry. Since the used baited traps are biased toward capturing larger size classes (cf. Hogger, 1988; Dorn et al., 2005), inter-population comparisons performed in our study were limited to adult and nearly adult part of the signal crayfish population, as is the case in many other studies of crayfish population structure and density (cf. Maguire et al., 2004 for references). Nevertheless, the standardized approach to trapping (same type of traps, baits, trap numbers and trapping period length) ensured that performed comparisons reflect differences between the catchable proportions of signal crayfish at examined sites.

Increasing male-bias toward the invasion front indicated differences in the sex ratio between established and establishing populations, and highlighted males as initial dispersers. The observed male bias in more recently established populations was further corroborated through a comparison of sex ratio between M1 and M2. Such maledominated sex ratios in more recently established populations have been observed for other invasive species (e.g., round goby; Gutowsky and Fox, 2011) including crayfish (e.g., in Orconectes limosus; Duriš et al., 2006), indicating similar population patterns with respect to sex structure in their range expansion. Male crayfish are more aggressive than females (e.g., Berry and Breithaupt, 2010) and compete intensely over resources such as food, shelter and mates (cf. Fero et al., 2007). Thus, social status could affect the spatial distribution of males (Fero and Moore, 2008), with subdominant individuals being the first to disperse. Moreover, body size is one of the important determinants of agonistic success and social status in crayfish (Vorburger and Ribi, 1999; Gherardi and Cioni, 2004; Davis and Huber, 2007). Since natural populations exhibit strong asymmetries in individual resource holding potential (Parker, 1974), it is also likely that initial dispersers could represent a non-random sample of population with regard to body size. The pattern of increase in the proportion of smaller-sized (size class 1) individuals toward the invasion front observed in this study would support the latter assumption. However, observed differences in population size structure were not statistically significant and these assumptions need to be tested further by including juveniles in future analyses.

Comparisons of measured parameters of animal size and weight demonstrated variability between analyzed population samples in the relative claw size for males. 
Claws represent one of the major fitness determinants in adult male crayfish. Larger chelae are not only advantageous in foraging, agonistic interactions and defense against the predators, but also in competition for females and copulation, resulting in a higher reproductive success (Garvey and Stein, 1993; Lee, 1995; Debuse et al., 2001; Streissl and Hödl, 2002). Relative claw size in males increased significantly from source population at M1 to population at the middle of examined invasive range at M2, demonstrating that median trait values of adults differ along the invasion pathway. Since investment in traits which promote dispersal or reproduction at the expanding front has been suggested by previous studies (e.g., Bøhn et al., 2004; Phillips et al., 2010), it is likely that investment in competitively advantageous morphological characteristic resulted in the observed increase of relative claw size in a more recently established population at M2. While proportional increase in relative claw size toward invasion front was observed for size class 1 males, the lack of such clear pattern in size class 2 males might be due to small sample size. Also, since allometric claw growth can continue after sexual maturity is reached (Harioglu and Holdich, 2001) smaller average size of size class 2 individuals at M3 could also contribute to the lack of such pattern. The recent establishment of population at M3 and the consequent low population density resulted in the small number of caught individuals despite the higher number of exposed traps at this site. This limited the use of data from invasion front only as a reference point in analyses of morphometric differences between populations. Low animal densities will represent a limitation to any future comparative studies involving sites at invasion front. Therefore, in order to provide more certainty in the expected patterns of relative claw size change at such sites, future research should investigate the optimal trapping methodology and required catch efforts at invasion front in large watercourses such as the Mura River.

As more recently established population samples were characterized with lower relative crayfish abundance, it is likely that local conditions represented an important selection pressure behind the recorded differences in the functionally important traits. Thus, the observed increase in the relative claw size in males toward invasion front might be associated with the lower competition intensity and higher resource availability at this site. Such conditions would allow for the higher growth rates (i.e., density-dependent growth; Guan and Wiles, 1999; Westman and Savolainen, 2002; Ramalho et al., 2008) and for a higher investment in claw growth. However, injuries to claws and exoskeleton did not differ either between the sexes or between the examined sites. The lack of expected increase in claw injuries toward population of the highest density (M1) (e.g., Figiel and Miller, 1995; Savolainen et al., 2004; Rypien and Palmer, 2007) indicates that observed morphometric differences in the relative claw size might also be correlated with certain behavioral traits (i.e., aggression). Such traits are selected during dispersal (cf. Pintor et al., 2009) since they are expected to benefit the social status and resource acquisition in hierarchically structured crayfish populations. Moreover, literature suggests that the rate of claw growth and differentiation is controlled by the same hormones which are positively correlated with aggressive behavior in crustaceans (ecdysteroids; Laufer and Ahl, 1995; Cromarty and Kass-Simon, 1998), further indicating a connection between these two traits. Therefore, in addition to the effect of local conditions, the observed increase in the relative claw size in more recently established population could also stem from non-random selection of aggressive individuals.

Our research highlights the importance of understanding the changes in population characteristics as invader advances its range. This could be of particular interest from the perspective of management efforts to control invasive species and conserve native fauna. In addition to helping determine how recently the population was established, differences in population characteristics and dynamics along the invasion pathway may call for different management options to effectively control the invasion. Along with the growing number of studies on other taxa (e.g., Phillips, 2009; Gutowsky and Fox, 2011), our results provide evidence for the existence of a trend among invasive species, suggesting that populations at different stages of establishment along invasive range exhibit similar differences in terms of their population structure. This could, in turn, indicate comparable mechanisms in their range expansion. Future studies, addressing for example local selection pressures as they relate to densitydependence or behavioral differences, will be needed to shed new light on the underlying causes of these trends. Identification of traits promoting invasion success and changes in population structure during dispersal is essential for improving our understanding of the exceptional speed at which invasive species such as signal crayfish are able to expand their range and encroach on the habitats of native species.

Acknowledgements. We thank the Public Service for Management of the Protected Areas in Međimurje County for their help in fieldwork organization and Tomislav Devčić for his help during fieldwork. We are very grateful to Lidija Novosel for helping out in the process of manuscript preparation and Mišel Jelić and Marko Ćaleta for making their work on potential crayfish predators in the Mura River available to us. Finally, we thank two anonymous reviewers for their helpful comments and suggestions. This research was realized through a project founded by Ministry of Science, Education and Sports (Project No. 119-1193080-1231).

\section{References}

Berry F. and Breithaupt T., 2010. To signal or not to signal? Chemical communication by urine-borne signals mirrors sexual conflict in crayfish. BMC Biol., 8, 25.

Bøhn T., Sandlund O.T., Amundsen P. and Primicerio R., 2004. Rapidly changing life history during invasion. Oikos, 106, 138-150. 
Burton O.J., Phillips B.L. and Travis J.M.J., 2010. Trade-offs and the evolution of life-histories during range expansion. Ecol. Lett., 13, 1210-1220.

Clobert J., Le Galliard J.F., Cote J., Meylan S. and Massot M., 2009. Informed dispersal, heterogeneity in animal dispersal syndromes and the dynamics of spatially structured populations. Ecol. Lett., 12, 197-209.

Cote J., Clobert J., Brodin T., Fogarty S. and Sih A., 2010a. Personality dependent dispersal: characterization, ontogeny and consequences for spatially structured populations. Phil. Trans. R. Soc. B., 365, 4065-4076.

Cote J., Weinersmith K., Brodin T. and Sih A., 2010b. Personality traits and dispersal tendency in the invasive mosquitofish (Gambusia affinis). Proc. R. Soc. B., 277, 1571-1579.

Crawford L., Yeomans W.E. and Adams C.E., 2006. The impact of introduced signal crayfish Pacifastacus leniusculus on stream invertebrate communities. Aquat. Conserv.: Mar. Freshwat. Ecosyst., 16, 611-621.

Cromarty S.I. and Kass-Simon G., 1998. Differential effects of a molting hormone, 20-hydroxyecdysone, on the neuromuscular junctions of the claw opener and abdominal flexor muscles of the American lobster. Comp. Biochem. Physiol. A, 120, 289-300.

Dana E.D., López-Santiago J., García-de-Lomas J., GarciaOcaña D.M., Gámez V. and Ortega F., 2010. Long-term management of the invasive Pacifastacus leniusculus (Dana, 1852) in a small mountain stream. Aquat. Invasions, 5, 317322.

Davis K. and Huber R., 2007. Activity patterns, behavioural repertoires, and agonistic interactions of crayfish: A nonmanipulative field study. Behaviour, 144, 229-247.

Debuse V.J., Addison J.T. and Reynolds J.D., 2001. Morphometric variability in UK populations of the European lobster. J. Mar. Biol. Assoc., 81, 469-474.

Diéguez-Uribeondo J., 2006. The dispersion of the Aphanomyces astaci-carrier Pacifastacus leniusculus by humans represents the main cause of disappearance of the indigenous crayfish Austropotamobius pallipes in Navarra. Bull. Fr. Peche Piscic., 380-381, 1303-1312.

Dorn N.J., Urgelles R. and Trexler J.C., 2005. Evaluating active and passive sampling methods to quantify crayfish density in a freshwater wetland. J. N. Am. Benthol. Soc., 24, 346-356.

Ďuriš Z., Drozd P., Horká I., Kozák P. and Policar T., 2006. Biometry and demography of the invasive crayfish Orconectes limosus in the Czech Republic. Bull. Fr. Peche. Piscic., 380-381, 1215-1228.

Fero K. and Moore P.A., 2008. Social spacing of crayfish in natural habitats: what role does dominance play?Behav. Ecol. Sociobiol., 62, 1119-1125.

Fero K., Simon J., Jourdie V. and Moore P.A., 2007. Consequences of social dominance on crayfish resource use. Behaviour, 144, 61-82.

Figiel C.R. and Miller G.R., 1995. The frequency of chela autotomy and its influence on the growth and survival of the crayfish Procambarus clarkii (Girard, 1852) (Decapoda, Cambaridae). Crustaceana, 68, 472-483.

Garvey J.E. and Stein R.A., 1993. Evaluating how chela size influences the invasion potential of an introduced crayfish (Orconectes rusticus). Am. Midl. Nat., 129, 172-181.

Gherardi F. and Cioni A., 2004. Agonism and interference competition in freshwater decapods. Behaviour, 141, 12971324.
Globevnik L. and Kaligarič M., 2005. Hydrological changes of the Mura River in Slovenia accompanied with habitat deteoration in the riverine space. Mater. Geoenviron., 52, 45-49.

Griffiths S.W., Collen P. and Armstrong J.D., 2004. Competition for shelter among over-wintering signal crayfish and juvenile Atlantic salmon. J. Fish Biol., 65, 436-447.

Guan R. and Wiles P.R., 1999. Growth and reproduction of the introduced crayfish Pacifastacus leniusculus in a British lowland river. Fish. Res., 42, 245-259.

Gutowsky L.F.G. and Fox M.G., 2011. Occupation, body size and sex ratio of round goby (Neogobius melanostomus) in established and newly invaded areas in an Ontario river. Hydrobiologia, 671, 27-37.

Harioglu M.M. and Holdich D.M., 2001. Meat yields in the introduced freshwater crayish, Pacifastacus leniusculus (Dana) and Astacus leptodactylus Eschscholtz, from British waters. Aquac. Res., 32, 411-417.

Hogger J.B., 1988. Ecology, population biology and behaviour. In: Holdich D.M. and Lowery R.S. (eds.), Freshwater crayfish: biology, management and exploitation, The University Press, Cambridge, 114-144.

Holdich D.M., Reynolds J.D., Souty-Grosset C. and Sibley P.J., 2009. A review of the ever increasing threat to European crayfish from non-indigenous crayfish species. Knowl. Manag. Aquat. Ecosyst., 394-395, 11.

Hudina S., Faller M., Lucić A., Klobučar G. and Maguire I., 2009. Distribution and dispersal of two invasive crayfish species in the Drava River basin, Croatia. Knowl. Manag. Aquat. Ecosyst., 394-395, 09.

Hudina S., Galic N., Roessink I. and Hock K., 2011. Competitive interactions between co-occurring invaders: identifying asymmetries between two invasive crayfish species. Biol. Invasions, 13, 1791-1803.

Jelić M., 2009. Distribution of otter (Lutra lutra L.) in the continental part of Croatia. Report for State Institute for Nature Protection, Zagreb, Croatia, 112 p.

Kolar C.S. and Loge D.M., 2002. Predictions and risk assessment for alien fishes in North America. Science, 298, 1233-1236.

Laufer H. and Ahl J.S.B., 1995. Mating behavior and methyl farnesoate levels in male morphotypes of the spider crab, Libinia emarginata (Leach). J. Exp. Mar. Biol. Ecol., 193, 15-20.

Lee S.Y., 1995. Cheliped size and structure: the evolution of a multifunctional decapod organ. J. Exp. Mar. Biol. Ecol., 193, 161-176.

Lockwood J.L., Hoopes M.F. and Marchetti M.P., 2007. Ecological processes and the spread of non-native species. In: Lockwood J.L., Hoopes M.F. and Marchetti M.P. (eds.), Invasion ecology, Blackwell Publishing, USA, 158-184.

Maguire I., Hudina S. and Erben R., 2004. Estimation of noble crayfish (Astacus astacus) population size in the Velika Paklenica Stream (Croatia). Bull. Fr. Peche. Piscic., 372-373, 353-366.

Marchetti M.P., Moyle P.B. and Levine R., 2004. Alien fishes in California watersheds: characteristics of successful and failed invaders. Ecol. Appl., 14, 587-596.

Mrakovčić M., Mustafić P., Ćaleta M., Zanella D., Buj I. and Marčić Z., 2008. Ichtiological biodiversity of the Mura River. University of Zagreb, Croatia, $125 \mathrm{p}$.

Parker G., 1974. Assessment strategy and the evolution of fighting behaviour. J. Theor. Biol., 47, 223-243. 
Phillips B.L., 2009. The evolution of growth rates on an expanding range edge. Biol. Lett., 5, 802-804.

Phillips B.L., Brown G.P. and Shine R., 2010. Life-history evolution in range-shifting populations. Ecology, 91, 16171627.

Pintor L.M., Sih A. and Bauer M., 2008. Differences in aggression, activity and boldness between native introduced populations of an invasive crayfish. Oikos, 117, $1629-1636$.

Pintor L., Sih A. and Kerby J., 2009. Behavioral correlations provide a mechanism for explaining high invasive densities and increased impact on native prey. Ecology, 90, 581-587.

Pöckl M., 1999. Distribution of crayfish species in Austria with special reference to introduced species. Freshw. Crayfish, 12, 733-750.

Pyšek P. and Richardson D.M., 2010. Invasive species, environmental change and management, and ecosystem health. Annu. Rev. Environ. Resour., 35, 25-55.

Ramalho R.O., Correia A.M. and Anastacio P.M., 2008. Effects of density on growth and survival of juvenile Red Swamp Crayfish, Procambarus clarkii (Girard), reared under laboratory conditions. Aquac. Res., 39, 577-586.

Rehage J.S. and Sih A., 2004. Dispersal behavior, boldness, and the link to invasiveness: a comparison of four Gambusia species. Biol. Invasions, 6, 379-391.

Ricciardi A., 2001. Facilitative interactions among aquatic invaders: is an "invasional meltdown" occurring in the Great Lakes? Can. J. Fish Aquat. Sci., 58, 2513-2525.

Rypien R.L. and Palmer A.R., 2007. The effect of sex, size and habitat on the incidence of puncture wounds in the claws oft he porcelain crab Petrolisthes cinctipes (Anomura: Porcellanidae). J. Crustac. Biol., 27, 59-64.

Sala O.E., Chapin F.S., Armesto J.J., Berlow J., Bloomfield J., Dirzo R., Huber-Sanwald E., Huenneke L.F., Jackson R.B., Kinzig A., Leemans R., Lodge D.M., Mooney H.A., Oesterheld M., Poff N.L., Sykes M.T., Walker B.H., Walker M., Wall D.H., 2000. Global biodiversity scenarios for the year 2100. Science, 287, 1770-1774.

Sallai Z., 2002. Investigation of the fish fauna of the Drava-Mura River System. Halászat, 95, 80-91.

Savolainen R., Ruohonen K., Railo E., 2004. Effect of stocking density on growth, survival and cheliped injuries of stage 2 juvenile signal crayfish Pasifastacus leniusculus Dana. Aquac. Res., 231, 237-248.

Schroeder L. and Huber R., 2001. Fighting strategies in small and large individuals of the crayfish, Orconectes rusticus. Behaviour, 128, 1437-1449.

Sint D., Dalla Via J. and Füreder L., 2007. Phenotypical characterization of indigenous freshwater crayfish populations. J. Zool., 273, 210-219.
Skurdal J., Taugbøl T., Fjeld E. and Qvenild T., 1988. Cheliped loss in Astacus astacus. Freshwat. Crayfish, 7, 165-170.

Söderbäck B., 1991. Interspecific dominance relationship and aggressive interactions in the freshwater crayfishes Astacus astacus (L.) and Pacifastacus leniusculus (Dana). Can. J. Zool., 69, 1321-1325.

Söderbäck B., 1995. Replacement of the native crayfish Astacus astacus by the introduced species Pacifastacus leniusculus in a Swedish lake: possible causes and mechanisms. Freshwat. Biol., 33, 291-304.

Sommerwerk N., Hein T., Schneider-Jacoby M., Baumgartner C., Ostojić A., Paunović M., Bloesch J., Siber R. and Tockner K., 2009. The Danube River Basin. In: Tockner K., Robinson C.T. and Uehlinger U. (eds.), Rivers of Europe, Elsevier Academic Press, Amsterdam, 59-112.

Souty-Grosset C., Holdich D., Noel P., Reynolds J.D. and Haffner P., 2006. Atlas of crayfish in Europe, Museum National d'Histoire Naturelle, Paris, 187 p.

Stancliffe-Vaughan A., 2009. Non-native crayfish - a community research and trapping initiative on the River Lark, Suffolk. Crayfish News: IAA Newsletter, 31, 5-7.

Strayer D.L., 2010. Alien species in fresh waters: ecological effects, interactions with other stressors, and prospects for the future. Freshwat. Biol., 55, 152-174.

Streissl F. and Hödl W., 2002. Growth, morphometrics, size at maturity, sexual dimorphism and condition index of Austropotamobius torrentium Schrank. Hydrobiologia, 477, 201-208.

Usio N., Konishi M. and Nakano S., 2001. Species displacement between an introduced and a 'vulnerable' crayfish: the role of aggressive interactions and shelter competition. Biol. Invasions, 3, 179-175.

Vorburger C. and Ribi G., 1999. Aggression and competition for shelter between a native and an introduced crayfish in Europe. Freshwat. Biol., 42, 111-119.

Weinländer M. and Füreder L., 2009. The continuing spread of Pacifastacus leniusculus in Carinthia (Austria). Knowl. Manag. Aquat. Ecosyst., 394-395, 17.

Westman K. and Savolainen R., 2002. Growth of the signal crayfish, Pacifastacus leniusculus, in a small forest lake in Finland. Boreal. Environ. Res., 7, 53-61.

Westman K., Pursiainen M. and Vilkman R., 1978. A new folding trap model which prevents crayfish from escaping. Freshwat. Crayfish, 4, 235-242.

Westman K., Savolainen R. and Pursiainen M., 1999. Development of the introduced North American signal crayfish, Pacifastacus leniusculus (Dana), population in a small Finnish forest lake in 1970-1977. Boreal. Environ. Res., 4, 387-407.

Zar J., 1996. Biostatistical analyses, Prentice Hall, London, $660 \mathrm{p}$. 